\title{
PENGARUH KOMPETENSI KEPRIBADIAN GURU TERHADAP \\ PRESTASI BELAJAR SISWA DI MTS AR-RIYADH 13 ULU \\ PALEMBANG
}

\begin{abstract}
Abstrak
Budi Agus Sumantri

Universitas Islam Negeri Sunan

Kalijaga Yogyakarta

\author{
Abdullah Idi dan Nurlaila \\ Universitas Islam Negeri Raden \\ Fatah Palembang
}

budisumantri0045@gmail.com

This study aims to determine the teacher's personal competency, student achievement, and the effect of teacher personality competency on student achievement at MTs ArRiyadh 13 Ulu Palembang. A teacher must have and be aware of the importance of competence teacher training especially personal competence. Many teachers master learning methodology well and have extensive knowledge of material taught, but not with a personality that reflects as a teacher who can be emulated and exemplary in the middle society especially students.

This type of research is a type of quantitative research. While secondary data sources are administrative staff, books and school documentation. The population in this study were all students of Ar-Riyadh MTs 13 Palembang Ulu. While the sample of this study was students of class VIII.A which amounted to 34 students. Data obtained by observation, questionnaire and documentation.

First, the data is collected, then recapitulated, then analyzed using statistics, namely by using the formula mean, standard deviation, TSR and percentage, and Product Moment. The results of this study are: first, the personality competencies of teachers in Ar-Riyadh MTs 13 Palembang Ulu are categorized as moderate or good enough because of the 34 respondents there were 21 respondents who stated medium (61.76\%). Second, student achievement in Ar-Riyadh MTs 13 Palembang Ulu is categorized as moderate or good enough because of the 34 respondents there were 22 respondents who were in the medium category or equal to (64.70\%). Third, there is a significant influence between teacher personality competencies on student achievement at Ar-Riyadh MTs 13 Palembang Ulu. Based on the results of statistical analysis that the " $r$ " table (Product Moment) of 0.489 is greater than the " $r$ " count both at the significance level of 5\% (0.349) and at the significance level of 1\% (0.449).
\end{abstract}

Keywords: Personality Competency, Teacher, Learning Outcomes 


\section{PENDAHULUAN}

Dalam Undang-Undang Guru dan Dosen ayat 2 dikemukakan bahwa kompetensi kepribadian adalah kemampuan pribadi yang mencakup kepribadian yang beriman dan bertakwa, berakhlak mulia, arif dan bijaksana, demokratis, mantap, berwibawa, stabil, dewasa, jujur, sportif, menjadi teladan bagi peserta didik dan masyarakat, secara obyektif mengevaluasi kinerja sendiri dan mengembangkan diri secara mandiri dan berkelanjutan. ${ }^{1}$

Menurut Syarnubi, kompetensi kepribadian adalah mempunyai kepribadian yang mantap, stabil, arif dan berwibawa hal itu dapat dilihat dari emosinya terjaga ketika menghadapi peserta didik yang bermasalah dalam proses pembelajaran di kelas. Mempunyai etos kerja yang tinggi dalam meningkatkan kualitas peserta didik, mempunyai rasa bangga menjadi guru yang senantiasa tiada henti-hentinya memberikan pengarahan dan bimbingan terhadap peserta didik. Selanjutnya Terbuka menerima saran dan kritik dari peserta didik, yaitu dengan cara memberikan waktu luang atau kesempatan untuk memberikan pendapat atau ide yang terkait dengan memajukan dan meningkatkan kualitas dalam proses pembelajaran. Dan pada akhirnya dapat menjadi tauladan bagi peserta didik dengan menampilkan akhlak yang baik di lingkungan sekolah maupun di masyarakat. $^{2}$

Kepribadian guru merupakan faktor yang menentukan terhadap keberhasilan dalam melaksanakan tugasnya sebagai pendidik, menurut Meicel Jhon, tidak seorangpun yang dapat menjadi seorang guru yang sejati kecuali ia menjadikan dirinya sebagai bagian dari anak didik yang berusaha untuk memahami seluruh anak didik dan kata-katanya. ${ }^{3}$ Tampilan kepribadian guru akan lebih banyak mempengaruhi minat dan antusiasme anak dalam mengikuti kegiatan pembelajaran. Pribadi guru yang santun, simpatik, respek terhadap siswa,

\footnotetext{
${ }^{1}$ Anggota IKPI, Undang-Undang Guru dan Dosen, (Bandung : Fokus Media, 2011), hlm. 66

${ }^{2}$ Syarnubi, S. (2019). Profesionalisme Guru Pendidikan Agama Islam Dalam Membentuk Religiusitas Siswa Kelas IV di SDN 2 Pengarayan. Tadrib, 5(1), 87-103.

${ }^{3}$ Akmal Hawi, Kompetensi Kepribadian Guru PAI, (Palembang: IAIN Raden Fatah Press, 2006), hlm. 17
} 
jujur, ikhlas dan dapat diteladani, mempunyai pengaruh terhadap keberhasilan dalam pembelajaran yang mempengaruhi langsung pada prestasi belajar mereka.

Dari sinilah masalah ketauladanan menjadi faktor penting dalam pembelajaran. Guru sebagai pendidik hendaklah dapat memberikan contoh yang baik dari dirinya sendiri, jangan hanya memberikan pengarahan semata, sementara ia sendiri tidak mengamalkannya. Dalam hal ini di jelaskan di dalam Al-Quran Surat Ash-Shaff ayat 3:4

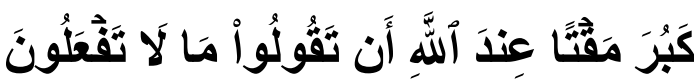

Artinya: "Amat besar kebencian di sisi Allah bahwa kamu mengatakan apa yang tidak kamu perbuat." (QS. Ash-Shaff). ${ }^{5}$

Dari ayat di atas jelas bahwa dalam memberikan pendidikan atau mengarahkan seseorang itu hendaklah dimulai dari diri kita sendiri sebelum kita menyuruh orang lain berbuat baik, hendaklah terlebih dahulu kita mengerjakan kebaikan tersebut.

Dari proses pembelajaran siswa dapat menghasilkan suatu perubahan yang bertahap dalam dirinya baik dalam bidang pengetahuan, keterampilan dan sikap. Adanya perubahan tersebut terlihat dalam prestasi belajar yang dihasilkan oleh siswa berdasarkan evaluasi yang diberikan oleh guru. Menurut Nana Sudjana, prestasi belajar merupakan penguasaan pengetahuan atau keterampilan yang dikembangkan melalui mata pelajaran, lazimnya ditunjukkan dengan nilai tes atau angka yang diberikan oleh guru. ${ }^{6}$

Dalam hal prestasi belajar siswa, kompetensi guru yang termasuk di dalamnya yaitu kompetensi kepribadian guru merupakan komponen yang sangat penting dalam proses pembelajaran. Kepribadian seorang guru, seperti pribadi yang bersifat terbuka, simpatik dan menarik, luwes, berwibawa, bijaksana, adil, arif dan sederhana termasuk sorotan utama yang bisa menciptakan suasana yang

\footnotetext{
${ }^{4}$ Ibid, hlm. 125
} hlm. 928.

${ }^{5}$ Departemen Agama RI, Al-Quran dan Terjemahannya, (Jakarta : Rilis Grafika, 2009),

${ }^{6}$ Nana Sudjana, Dasar-Dasar Proses Belajar Mengajar, (Bandung: Sinar Baru Algensindo, 2005), hlm. 52 
tenang, dan menyenangkan yang dibutuhkan oleh siswa, yang akhirnya memberikan dorongan kesenangan siswa pada mata pelajaran guru tersebut.

Sikap guru hendaknya mengetahui dan menyadari betul akan peran dan kepribadiannya dalam mengajar sangat menentukan tercapai atau tidaknya tujuan pendidikan yang hendak dicapai dalam lembaga pendidikan tempat ia mengajar khususnya. ${ }^{7}$ kompetensi kepribadian yang dicerminkan oleh guru melalui sifatnya yang terbuka, simpatik, luwes, menarik, berwibawa, adil dan bijaksana merupakan sifat yang dibutuhkan siswa dalam diri seorang guru, untuk menambah kesemangatan mereka dalam proses belajar mengajar yang semua itu berpengaruh pula pada prestasi belajar siswa.

Penelitian tentang kompetensi guru sudah pernah diteliti oleh beberapa peneliti, diantaranya: Hendra (2004), melakukan penelitian dengan judul Kompetensi Guru Pendidikan Agama Islam di Madrasah Aliyah Negeri 2 Pekanbaru, hasil penelitiannya adalah kompetensi guru pendidikan agama islam di Madrasah Aliyah Negeri 2 Pekanbaru tergolong baik

Pentingnya kualitas kepribadian seorang guru dalam proses belajar mengajar dengan harapan dapat mendorong siswa untuk belajar dan untuk meningkatkan prestasi belajar dengan maksimal, sehingga perlu dilakukan penelitian tentang pengaruh kompetensi kepribadian guru dengan prestasi belajar siswa, meskipun bukan sesuatu yang mudah untuk mengukur dan menilai aspek-aspek kepribadian guru, namun setidaknya usaha untuk mengungkap kompetensi kepribadian guru melalui tanggapan siswa merupakan salah satu usaha untuk memperoleh gambaran tentang kepribadian guru yang diharapkan siswa. Dengan hasil penelitian ini guru diharapkan dapat mengembangkan kepribadiannya, dan guru dapat meningkatkan mutu pelayanan pendidikan yang diberikan secara lebih baik demi keberhasilan dalam mengembangkan dirinya secara optimal.

${ }^{7}$ Akmal Hawi, Op. Cit., hlm. 69 


\section{METODE PENELITIAN}

Penelitian ini adalah penelitian kuantitatif yaitu jenis penelitian yang berlandaskan pada filsafat positivisme digunakan untuk meneliti pada populasi atau sampel tertentu, teknik pengambilan sampel pada umumnya dilakukan secara random, pengumpulan data dilakukan secara instrument penelitian, analisis data bersifat kuantitatif/statistic dengan tujuan untuk menguji hipotesis yang telah diterapkan. ${ }^{8}$ karena penulis akan menggambarkan sekaligus menganalisis antara kompetensi kepribadian guru dengan prestasi belajar siswa di MTs Ar-riyadh 13 Ulu Palembang.

Jenis data yang digunakan dalam penelitian ini ialah kuantitatif. Kuantitatif adalah data hasil pengukuran yang dinyatakan dalam angka-angka. ${ }^{9}$ Penelitian ini menggunakan data kuantitatif berupa data yang menunjukkan angka yang berkaitan dengan permasalahan yang di teliti. Sumber data dalam penelitian ini diklasifikasikan pada sumber data primer dan sumber data sekunder. Sumber data primer, yaitu data statistik yang diperoleh atau bersumber dari tangan pertama (first hand data) ${ }^{10}$. Data diperoleh langsung dari siswa kelas VIII di MTs Ar-Riyadh13 Palembang yang bersangkutan di tempat penelitian. Dan sumber data sekunder adalah data statistik yang bersumber dari tangan kedua (second hand data). ${ }^{11}$ Sumber data sekunder diambil melalui dokumentasi sekolah, administrasi sekolah, buku-buku serta dokumentasi yang layak dijadikan sumber data.

Populasi adalah wilayah generalisasi yang terdiri dari obyek atau subyek yang menjadi kuantitas dan karakteristik tertentu yang ditetapkan oleh peneliti untuk dipelajari dan kemudian ditarik kesimpulannya. ${ }^{12}$ Adapun populasi dalam penelitian ini adalah seluruh siswa kelas VIII Mts dengan jumlah 162 siswa. Sedangkan sampel adalah bagian dari jumlah dan karakteristik yang dimiliki oleh

\footnotetext{
${ }^{8}$ Sugiyono, Metode Penelitian Pendidikan ( pendekatan kuantitatif, kualitatif dan $R n D$ ), (Bandung:Alfabeta, 2014), hlm.14

${ }^{9}$ Saipul Annur, Op.Cit.., hlm. 125 2014), hlm. 19

${ }^{10}$ Anas Sudijono, Pengantar Statistik Pendidikan, (Jakarta:PT Raja Grafindo Persada,

${ }^{11}$ Ibid.,

${ }^{12}$ Supardi, Aplikasi Statistika Dalam Penelitian Konsep Statistik Yang Lebih Komprehensif, (Jakarta: PT. Prima Ufuk Semesta, 2013), hlm. 25
} 
populasi tersebut. Bila populasi besar, dan peneliti tidak mungkin mempelajari semua yang ada pada populasi, maka peneliti dapat menggunakan sampel yang diambil dari populasi itu. Apa yang dipelajari dari sampel itu, kesimpulannya akan dapat diberlakukan untuk populasi. ${ }^{13}$. Penarikan sampel ini mengacu pada teknik purposive sampling yaitu teknik pengambilan sampel dengan sengaja. Peneliti menentukan sendiri sampel yang diambil secara tidak acak, tetapi ditentukan sendiri oleh peneliti. Adapun sampel dari penelitian ini yaitu siswa kelas VIII A.

Teknik merupakan pengetahuan dan kepandaian membuat sesuatu yang berkenaan dengan hasil industri, bangunan-bangunan dan mesin. Pengumpulan data adalah suatu proses pengumpulan data primer dan sekunder. ${ }^{14}$ Dalam penelitian ini, penulis menggunakan beberapa metode sesuai dengan sifat dari data yang dihimpun metode tersebut adalah: ${ }^{15}$ Observasi, angket, dan dokumentasi.

Teknik analisis data merupakan cara menganalisis data penelitian, termasuk ala-alat statistik yang relevan untuk digunakan dalam penelitian. ${ }^{16}$ Setelah data terkumpul melalui metode-metode di atas, kemudian dilakukan analisis yakni dengan menggunakan analisis statistik yakni dengan menggunakan rumus: ${ }^{17}$

$$
\begin{aligned}
& r_{x y}=\mathrm{n}\left(\sum x y\right)-\left(\sum x \cdot \sum y\right) \\
& \sqrt{\left[n \sum x^{2}\left(\sum x\right)^{2} n \sum y^{2}-\left(\sum y\right)^{2}\right.}
\end{aligned}
$$

Keterangan:

$\mathrm{n} \quad$ = Banyaknya pasang data (unit sampel)

$\mathrm{x} \quad=$ Variabel bebas

$\mathrm{y} \quad=$ Variabel terikat

\footnotetext{
${ }^{13}$ Ibid., hlm. 118

${ }^{14}$ Syofian Siregar, Metode Penelitian Kuantitaif (Dilengkapi Perbandingan Perhitungan Manual \& SPSS), (Jakarta: Kencana Prenadamedia Group, 2014), hlm. 17

${ }^{15}$ Ibid, hlm. 18

${ }^{16}$ Juliansyah Noor, Metodologi Penelitian (Skripsi, Tesis, Desertasi dan Karya Ilmiah), (Jakarta : Kencana Prenadamedia Group, 2014), hlm. 163

${ }^{17}$ Syofian Siregar, Op., Cit. hlm. 252
} 


\section{HASIL DAN PEMBAHASAN}

\section{A. Kompetensi Kepribadian Guru MTs Ar-Riyadh 13 Ulu Palembang}

Untuk mengetahui kompetensi kepribadian guru di MTs Ar-Riyadh 13 Ulu Palembang, peneliti juga menyebarkan angket dengan 20 item pertanyaan kepada responden. Hasilnya dapat dilihat sebagai berikut:

$\begin{array}{llllllllll}47 & 56 & 70 & 54 & 62 & 65 & 64 & 47 & 56 & 53 \\ 69 & 49 & 60 & 69 & 57 & 54 & 55 & 55 & 55 & 73 \\ 71 & 67 & 66 & 56 & 67 & 58 & 41 & 61 & 62 & 58 \\ 51 & 65 & 50 & 66 & & & & & & \end{array}$

Dari data di atas dapat diketahui bahwa skor tertinggi adalah 73 dan skor terendah adalah 41. Setelah itu data tersebut akan diolah menggunakan rumus sebagai berikut:

Tabel. 8

Distribusi Frekuensi Kompetensi Kepribadian Guru di MTs Ar-Riyadh 13 Ulu Palembang

\begin{tabular}{|c|c|c|c|c|c|c|}
\hline Nilai & $\mathbf{F}$ & $\mathbf{X i}$ & $\mathbf{F i . X i}$ & $(\mathbf{X}-\overline{\boldsymbol{X}})$ & $(\mathbf{X i}-\overline{\boldsymbol{X}})^{\mathbf{2}}$ & $\mathbf{f .}(\mathbf{X i}-\overline{\boldsymbol{X}})^{\mathbf{2}}$ \\
\hline $41-46$ & 1 & 43,5 & 43,5 & $-15,88$ & 252.17 & 252,17 \\
\hline $47-52$ & 5 & 49,5 & 247,5 & $-9,88$ & 97,61 & 488,05 \\
\hline $53-58$ & 12 & 55,5 & 666 & $-3,88$ & 15,05 & 180,6 \\
\hline $59-64$ & 5 & 61,5 & 307,5 & -2.12 & 4,49 & 22,45 \\
\hline $65-70$ & 9 & 67,5 & 607,5 & 8,12 & 65,93 & 593,37 \\
\hline $71-76$ & 2 & 73,5 & 147 & 14,12 & 199,37 & 398,74 \\
\hline Jumlah & $\mathbf{3 4}$ & & $\mathbf{2 0 1 9}$ & & $\mathbf{6 3 4 , 6 2}$ & $\mathbf{1 . 9 3 5 . 3 8}$ \\
\hline
\end{tabular}

1. Mencari me an dengan rumus:

$$
\begin{aligned}
\bar{X} & =\frac{\sum f_{i} X_{i}}{\sum f_{i}} \\
& =\frac{2019}{34}=59,38
\end{aligned}
$$

2. Mencari standar deviasi (simpangan baku) dengan rumus:

$$
\mathrm{s}=\frac{\sqrt{\sum f_{i}}\left[X_{i}-\overline{X]}^{2}\right.}{\left(\sum f_{i}\right)-1}
$$




$$
=\sqrt{\frac{1.935 .38}{34-1}}=\sqrt{58,65}=7,658
$$

Setelah nilai rata-rata (mean) dan standar deviasi (SD) diketahui, maka untuk mengetahui tingkat kompetensi kepribadian guru di MTs Ar-Riyadh 13 Ulu Palembang dalam kategori tinggi, sedang dan rendah maka skor dianalisa dengan menggunakan rumus TSR sebagai berikut:

a. Indikasi yang tergolong kategori tinggi

$$
\mathrm{M}+1 . S D_{x}=\text { tinggi }
$$

$59,38+1 .(7,658)=67,03$ dibulatkan menjadi 67 ke atas (tinggi)

b. Indikasi yang tergolong kategori sedang

Nilai yang diantara nilai tinggi dan rendah yaitu 52-67

c. Indikasi yang tergolong kategori rendah

$\mathrm{M}-1 . S D_{x}=$ rendah

$59,38-1$. $(7,658)=51,72$ dibulatkan menjadi 52 ke bawah (rendah)

Tabel. 9

Distribusi Frekuensi Skor dan Persentase TSR

\begin{tabular}{|c|c|c|}
\hline Klasifikasi & Frekuensi & Persentase \\
\hline Tinggi & 7 & $20,58 \%$ \\
\hline Sedang & 21 & $61,76 \%$ \\
\hline Rendah & 6 & $17,64 \%$ \\
\hline Jumlah & $\mathbf{3 4}$ & $\mathbf{1 0 0} \%$ \\
\hline
\end{tabular}

Dari tabel diatas dapat diketahui bahwa kompetensi kepribadian guru di MTs Ar-Riyadh 13 Ulu Palembang tergolong dalam kategori sedang. Hal ini terlihat dari distribusi frekuensi skor dan persentasi TSR dimana ada 7 siswa $(20,58 \%)$ yang menjawab tinggi, 21 siswa $(61,76 \%)$ yang menjawab sedang dan ada 6 siswa (17,64\%) yang menjawab rendah. Oleh karena itu dari uraian di atas dapat diperoleh kesimpulan bahwa kompetensi kepribadian guru di MTs ArRiyadh 13 ulu Palembang tergolong baik. 


\section{B. Prestasi Belajar Siswa MTs Ar-Riyadh 13 Ulu Palembang}

Untuk mengetahui prestasi belajar siswa di MTs Ar-Riyadh 13 ulu Palembang, peneliti mengambil dari hasil ujian semester ganjil siswa kelas VIII. A MTs Ar-Riyadh 13 Ulu Palembang. Hasilnya dapat dilihat sebagai berikut:

$\begin{array}{llllllllll}80 & 70 & 65 & 76 & 78 & 86 & 78 & 83 & 80 & 77 \\ 80 & 78 & 77 & 82 & 78 & 87 & 78 & 70 & 70 & 82 \\ 78 & 80 & 80 & 80 & 86 & 60 & 80 & 60 & 80 & 65 \\ 76 & 82 & 65 & 76 & & & & & & \end{array}$

Dari data di atas dapat diketahui bahwa skor tertinggi adalah 87 dan skor terendah adalah 60. Setelah itu data tersebut akan diolah menggunakan rumus sebagai berikut:

Tabel. 10

Distribusi Frekuensi Prestasi Belajar Siswa MTs Ar-Riyadh 13 Ulu Palembang

\begin{tabular}{|c|c|c|c|c|c|c|}
\hline Nilai & $\mathbf{F}$ & $\mathbf{Y i}$ & $\mathbf{F i} . \mathbf{Y} \mathbf{i}$ & $\mathbf{( Y - \overline { Y } )}$ & $(\mathbf{Y i}-\overline{\boldsymbol{Y}})^{\mathbf{2}}$ & $\mathbf{f .}(\mathbf{X i}-\overline{\boldsymbol{Y}})^{\mathbf{2}}$ \\
\hline $60-64$ & 2 & 62 & 124 & $-15,44$ & 238,39 & 476,78 \\
\hline $65-69$ & 3 & 67 & 201 & $-10,44$ & 108,99 & 326,97 \\
\hline $70-74$ & 3 & 72 & 216 & $-5,44$ & 29,59 & 88,77 \\
\hline $75-79$ & 11 & 77 & 847 & $-0,44$ & 0,19 & 14,63 \\
\hline $80-84$ & 12 & 82 & 984 & 20,79 & 20,79 & 249,48 \\
\hline $85-89$ & 3 & 87 & 261 & 9,56 & 91.39 & 274,17 \\
\hline Jumlah & $\mathbf{3 4}$ & & $\mathbf{2 6 3 3}$ & & $\mathbf{4 8 9 , 3 4}$ & $\mathbf{1 4 3 0 , 8}$ \\
\hline
\end{tabular}

1. Mencari mean dengan rumus:

$$
\begin{aligned}
\bar{X} & =\frac{\sum f_{i} Y_{i}}{\sum f_{i}} \\
& =\frac{2633}{34}=77,44
\end{aligned}
$$

2. Mencari standar deviasi (simpangan baku) dengan rumus:

$$
\begin{aligned}
\mathrm{s} & =\frac{\sqrt{\sum f_{i}}\left[Y_{i}-\bar{Y}^{2}\right.}{\left(\sum f_{i}\right)-1} \\
& =\sqrt{\frac{1430,8}{34-1}}=\sqrt{43}, 36=6,584
\end{aligned}
$$


Setelah nilai rata-rata (mean) dan standar deviasi (SD) diketahui, maka untuk mengetahui tingkat prestasi belajar siswa MTs Ar-Riyadh 13 Ulu Palembang dalam kategori tinggi, sedang dan rendah maka skor dianalisa dengan mengunakan rumus TSR sebagai berikut:

a. Indikasi yang tergolong kategori tinggi

$\mathrm{M}+1 . S D_{x}=$ tinggi

$77,44+1 .(6,584)=$ dibulatkan menjadi 84,02 ke atas (tinggi)

b. Indikasi yang tergolong kategori sedang

Nilai yang diantara nilai tinggi dan rendah yaitu $71-84$

c. Indikasi yang tergolong kategori rendah

$\mathrm{M}-1 . S D_{x}=$ rendah

$77,44-1$. $(6,584)=70,85$ dibulatkan menjadi 71 ke bawah (rendah)

Tabel. 11

Distribusi Frekuensi Skor dan Persentase TSR

\begin{tabular}{|c|c|c|}
\hline Klasifikasi & Frekuensi & Persentase \\
\hline Tinggi & 4 & $11,76 \%$ \\
\hline Sedang & 22 & $64,70 \%$ \\
\hline Rendah & 8 & $23,52 \%$ \\
\hline Jumlah & $\mathbf{3 4}$ & $\mathbf{1 0 0} \%$ \\
\hline
\end{tabular}

Dari tabel diatas dapat diketahui bahwa prestasi belajar di MTs Ar-Riyadh 13 Ulu Palembang tergolong dalam kategori sedang. Hal ini terlihat dari distribusi frekuensi skor dan persentasi TSR dimana ada 4 siswa (11,76 \%) yang termasuk kategori tinggi, 22 siswa $(64,70 \%)$ yang termasuk kategori sedang dan ada 8 siswa $(23,52 \%)$ yang termasuk kategori rendah. Oleh karena itu dari uraian di atas dapat diperoleh kesimpulan bahwa prestasi belajar siswa di MTs Ar-Riyadh 13 Ulu Palembang tergolong dalam kategori sedang.

\section{Pengaruh Kompetensi Kepribadian Guru Terhadap Prestasi Belajar Siswa di MTs Ar-Riyadh 13 Ulu Palembang}

Setelah dilakukan analisis mengenai kompetensi kepribadian guru dan Prestasi Belajar siswa. Selanjutnya untuk membuktikan bagaimana pengaruh antara kompetensi kepribadian guru terhadap prestasi belajar siswa di MTs Ar- 
Vol. 1, No. 3 (Agustus 2019): 294-309

Riyadh 13 Ulu Palembang, maka analisis data pada penelitian ini menggunakan rumus statistik yaitu "product-moment" antara kompetensi kepribadian guru dengan prestasi belajar siswa sebagai berikut:

1. Mencari Nilai Statistik Dasar (SD)

Adapun pengaruh kompetensi kepribadian guru terhadap aspek nilai kejujuran siswa diperoleh dari nilai statistik dasar sebagai berikut.

Tabel. 12

Tabel Perhitungan Untuk Mencari Angka Indeks Korelasi antara Variabel X dan Variabel Y

\begin{tabular}{|c|c|c|c|c|c|}
\hline No & $\mathbf{X}$ & $\mathbf{Y}$ & $\mathbf{X Y}$ & $\boldsymbol{X}^{\mathbf{2}}$ & $\boldsymbol{Y}^{\mathbf{2}}$ \\
\hline 1 & 47 & 80 & 3760 & 2209 & 6400 \\
\hline 2 & 56 & 70 & 3920 & 3136 & 4900 \\
\hline 3 & 70 & 65 & 4550 & 4900 & 4225 \\
\hline 4 & 54 & 76 & 4104 & 2916 & 5776 \\
\hline 5 & 62 & 78 & 4836 & 3844 & 3844 \\
\hline 6 & 65 & 86 & 5590 & 4225 & 7396 \\
\hline 7 & 64 & 78 & 4992 & 4096 & 6084 \\
\hline 8 & 47 & 83 & 3901 & 2209 & 6889 \\
\hline 9 & 56 & 80 & 4480 & 3136 & 6400 \\
\hline 10 & 53 & 77 & 4081 & 2809 & 5929 \\
\hline 11 & 69 & 80 & 5520 & 4761 & 6400 \\
\hline 12 & 49 & 78 & 3822 & 2401 & 6084 \\
\hline 13 & 60 & 77 & 4620 & 3600 & 5929 \\
\hline 14 & 69 & 82 & 5658 & 4761 & 6724 \\
\hline 15 & 57 & 78 & 4446 & 3249 & 6084 \\
\hline 16 & 54 & 87 & 4698 & 2916 & 7569 \\
\hline 17 & 55 & 78 & 4290 & 3025 & 6084 \\
\hline 18 & 55 & 70 & 3850 & 3025 & 4900 \\
\hline 19 & 55 & 70 & 3850 & 3025 & 4900 \\
\hline 20 & 73 & 82 & 5986 & 5329 & 6724 \\
\hline 21 & 71 & 78 & 5538 & 5041 & 6084 \\
\hline 22 & 67 & 80 & 5360 & 4489 & 6400 \\
\hline 23 & 66 & 80 & 5280 & 4356 & 6400 \\
\hline 24 & 56 & 80 & 4480 & 3136 & 6400 \\
\hline 25 & 67 & 86 & 5762 & 4489 & 7396 \\
\hline 26 & 58 & 60 & 4380 & 3364 & 3600 \\
\hline 27 & 41 & 80 & 3280 & 1681 & 6400 \\
\hline 28 & 61 & 60 & 3660 & 3721 & 3600 \\
\hline 29 & 62 & 80 & 4960 & 3844 & 6400 \\
\hline 30 & 58 & 65 & 3770 & 3364 & 4225 \\
\hline
\end{tabular}




\begin{tabular}{|c|c|c|c|c|c|}
\hline 31 & 51 & 76 & 3876 & 2601 & 5776 \\
\hline 32 & 65 & 82 & 5330 & 4225 & 6724 \\
\hline 33 & 50 & 65 & 3250 & 2500 & 4225 \\
\hline 34 & 66 & 76 & 5016 & 4356 & 5776 \\
\hline$\sum$ & 2009 & 2603 & 154896 & 126513 & 198647 \\
\hline
\end{tabular}

$H_{a}$ : Terdapat pengaruh yang signifikan antara kompetensi kepribadian guru terhadap prestasi belajar siswa di MTs Ar-Riyadh 13 Ulu Palembang

$H_{o}$ : Tidak terdapat pengaruh yang signifikan antara kompetensi kepribadian guru terhadap prestasi belajar siswa di MTs Ar-Riyadh 13 Ulu Palembang

2. Mencari Product Moment

$$
\begin{aligned}
r_{x y} & =\frac{\mathrm{n}\left(\sum x y\right)-\left(\sum x \cdot \sum y\right)}{\sqrt{\left[n \sum x^{2}-\left(\sum x\right)^{2} n \sum y^{2}-\left(\sum y\right)^{2}\right.}} \\
& =\frac{34 \cdot(154896)-(2009.2603)}{\sqrt{\left[34 \cdot 126513-(2009)^{2}\right]\left[34.198647-(2603)^{2}\right]}} \\
& =\frac{5266464-5229427}{\sqrt{4301442-403608.6753998-6775609}} \\
& =\frac{37037}{\sqrt{265361.21611}} \\
& =\frac{37037}{\sqrt{5734716571}} \\
& =\frac{37037}{75727,91} \\
= & 0,489
\end{aligned}
$$

Setelah diketahui nilai $r_{x y}$ maka selanjutnya untuk memberikan interpretasi terhadap nilai di atas maka dapat dilihat nilai "r" tabel (Product Moment) baik pada taraf signifikasi 5\% maupun pada taraf signifikasi 1\% yang maksudnya keputusan untuk mendukung atau menolak hipotesis nol memiliki probabilitas kesalahan sebesar 5\% dan 1\% dengan menghitung df-nya terlebih dahulu dengan rumus $\mathrm{df}=\mathrm{N}-2$ yaitu $34-2=32$ terdapat dalam tabel. Dengan $\mathrm{df}$ $=32$ diperoleh pada taraf signifikasi 5\% sebesar 0,349 dan taraf signifikasi $1 \%$ sebesar 0,449. Dari hasil tersebut terlihat bahwa $r_{x y} 0,489$ lebih besar dari taraf 
signifikasi $5 \%$ dan taraf signifikasi $1 \%$ dengan perbandingan $0,349<0,489>$ 0,449 .

Dengan demikian maka hipotesa alternatif $H_{a}$ diterima yang berarti ada pengaruh positif yang signifikan antara variabel $\mathrm{X}$ (Kompetensi Kepribadian Guru) terhadap variabel Y (Prestasi belajar Siswa). Dengan demikian apabila kompetensi kepribadian guru baik maka prestasi belajar siswa juga akan baik.

a. Uji Hipotesis

Untuk menguji hipotesis digunakan Uji $\mathrm{T}$. Uji t digunakan untuk menguji dua hipotesis yang diajukan yaitu hipotesis pertama dan hipotesis kedua. Dalam penelitian ini, uji $\mathrm{t}$ yang digunakan bertujuan untuk membandingkan besarnya pengaruh suatu perlakuan berupa penggunaan media pembelajaran video interaktif dalam proses pembelajaran.

Kriteria pengujian yang berlaku adalah Ho diterima jika $t_{\text {hitung }}<t_{\text {tabel }}$ dengan menentukan $\mathrm{dk}=\mathrm{n} 2+\mathrm{n} 2-2$, taraf signifikasi $5 \%$.

Hipotesis yang dikemukakan peneliti dalam penelitian ini sebagai berikut:

Ho Tidak terdapat pengaruh penggunaan media pembelajaran audio visual tehadap aktivitas pembelajaran siswa pada mata pelajaran Pendidikan Agama Islam kelas VIII di SMP Negeri 3 Palembang.

Ha Terdapat pengaruh penggunaan media pembelajaran audio visual terhadap aktivitas pembelajaran siswa pada mata pelajaran Pendidikan Agama Islam kelas VIII di SMP Negeri 3 Palembang.

Untuk mencari thitung sebelumnya dicari varians gabungan dari kedua data dengan rumus sebagai berikut:

$$
\begin{aligned}
S^{2} & =\frac{\left(n_{1}-1\right) S_{1}^{2}+\left(n_{2}-1\right) S_{2}^{2}}{\left(n_{1}+n_{2}\right)-2} \\
& =\frac{(38-1) 38.69+(38-1) 39.48}{(38+38)-2} \\
& =\frac{1431.53+1460.76}{74}
\end{aligned}
$$




$$
\begin{aligned}
& =\frac{2892.29}{74} \\
& =39.085 \\
S & =\sqrt{39.085} \\
& =6.25
\end{aligned}
$$

Simpangan baku $=6.25$

$$
\begin{aligned}
\mathrm{t} & =\frac{\mathrm{x}_{1}-\mathrm{x}_{2}}{\mathrm{~S} \sqrt{\frac{1}{\mathrm{n}_{1}}+\frac{1}{\mathrm{n}_{2}}}} \\
& =\frac{66.7-60.2}{6.25 \sqrt{\frac{1}{38}+\frac{1}{38}}} \\
& =\frac{6.5}{6.25 \sqrt{\frac{2}{38}}} \\
& =\frac{6.5}{6.25(\sqrt{0.053})} \\
& =\frac{6.5}{6.25(0.23)} \\
& =\frac{6.5}{1.44} \\
& =4.514
\end{aligned}
$$

Jadi, diketahui thitung sebesar 4,514

Setelah mendapatkan $t_{\text {hitung }}$ maka langkah selanjutnya mencari $t_{\text {tabel }}$ dengan ketentuan sebagai berikut:

$$
\begin{aligned}
& \mathrm{dk}=\mathrm{n} 1+\mathrm{n} 2-2 \\
& \mathrm{dk}=38+38-2 \\
& \mathrm{dk}=74 \\
& \text { jadi, dk yaitu } 74
\end{aligned}
$$

Berdasarkan perhitungan dengan rumus uji-t pada skor angket diperoleh $\mathrm{t}_{\text {hitung }}$ sebesar 4.514 kemudian dikonsultasikan dengan $\mathrm{t}_{\text {tabel }}$ dengan $\mathrm{dk}=(\mathrm{n} 1+\mathrm{n} 2-2)$ atau 38+38-2=74 dengan taraf signifikasi 5\% yaitu 1.992 . Setelah dikonsultasikan ternyata $t_{\text {hitung }}>t_{\text {tabel }}$ atau $4.514>1.992$. Hal ini berarti Ho ditolak dan Ha diterima yang menyatakan "Terdapat pengaruh penggunaan media pembelajaran audio visual terhadap aktivitas pembelajaran siswa pada mata pelajaran Pendidikan Agama Islam kelas VIII di SMP Negeri 3 Palembang.”. 


\section{SIMPULAN}

Berdasarkan uraian dan analisa bab sebelumnya maka dapat ditarik kesimpulan sebagai berikut:

Kompetensi kepribadian guru di MTs Ar-Riyadh 13 Ulu Palembang dikategorikan sedang atau baik karena dari 34 responden terdapat 7 responden yang menyatakan tinggi sebesar (20,58\%). Sedangkan 21 responden atau sebesar $(61,76 \%)$ terkategori sedang. Kemudian untuk kategori rendah terdapat 6 responden atau sebesar $(17,64 \%)$.

Prestasi belajar siswa di MTs Ar-Riyadh 13 Ulu Palembang dikategorikan sedang atau cukup baik karena dari 34 responden terdapat 22 responden yang termasuk kategori sedang atau sebesar $(64,70 \%)$. Sedangkan 4 responden atau sebesar $(11,76 \%)$ terkategori tinggi atau sangat baik. Kemudian untuk kategori rendah terdapat 8 responden atau sebesar $(23,52 \%)$.

Ada pengaruh yang signifikan antara kompetensi kepribadian guru terhadap prestasi belajar siswa di MTs Ar-Riyadh 13 Ulu Palembang. Berdasarkan hasil analisa statistik bahwa "r" tabel (Product Moment) 0,489 lebih besar dari pada " $r$ " hitung baik pada taraf signifikasi 5\% $(0,349)$ maupun pada taraf signifikasi $1 \%(0,449)$. Dengan demikian maka hipotesa alternatif $H_{a}$ diterima yang berarti ada pengaruh yang signifikan antara kompetensi kepribadian guru terhadap prestasi belajar siswa di MTs Ar-Riyadh 13 Ulu Palembang. 


\section{DAFTAR PUSTAKA}

Anggota IKPI. (2011). Undang-Undang Guru dan Dosen. Bandung: Fokus Media.

Ramayulis. (2013). Profesi \& Etika Keguruan. Jakarta: Kalam Mulia.

Hawi, Akmal. (2006). Kompetensi Kepribadian Guru PAI. Palembang: IAIN Raden Fatah Press.

Departemen Agama RI. (2009). Al-Quran dan Terjemahannya. Jakarta: Rilis Grafika.

Sudjana, Nana. (2005). Dasar-Dasar Proses Belajar Mengajar, Bandung: Sinar Baru Algensindo.

Sugiyono. (2014). Metode Penelitian Pendidikan (pendekatan kuantitatif, kualitatif dan $R n D$ ). Bandung:Alfabeta.

Sudijono, Anas. (2014). Pengantar Statistik Pendidikan, Jakarta:PT Raja Grafindo Persada.

Supardi. (2013). Aplikasi Statistika Dalam Penelitian Konsep Statistik Yang Lebih Komprehensif. Jakarta: PT. Prima Ufuk Semesta, 2013.

Siregar, Syofian. (2014). Metode Penelitian Kuantitaif (Dilengkapi Perbandingan Perhitungan Manual \& SPSS). Jakarta: Kencana Prenadamedia Group.

Syarnubi, S. (2019). Profesionalisme Guru Pendidikan Agama Islam Dalam Membentuk Religiusitas Siswa Kelas IV di SDN 2 Pengarayan. Tadrib, 5(1), 87-103.

Noor, Juliansyah. (2014). Metodologi Penelitian (Skripsi, Tesis, Desertasi dan Karya Ilmiah). Jakarta: Kencana Prenadamedia Group, 2014. 